\title{
EDUCAÇÃO ESCOLAR E GESTÃO DEMOCRÁTICA DO ENSINO: PERSPECTIVAS
}

\author{
EDUCACIÓN ESCOLAR Y GESTIÓN DEMOCRÁTICA DE LA ENSEÑANZA: \\ PERSPECTIVAS
}

\section{SCHOOL EDUCATION AND DEMOCRATIC MANAGEMENT OF TEACHING: PERSPECTIVES}

\author{
Máximo Augusto Campos MASSON ${ }^{1}$ \\ Maria Teresa Vianna VAN ACKER ${ }^{2}$
}

RESUMO: O artigo discute a gestão do ensino a partir do debate sobre a gestão democrática de instituições sociais, em particular, a escola. Reflete sobre as mudanças ocorridas na escola em função da presença de novos alunos, pertencentes às classes subalternas e a possibilidade da gestão democrática do ensino ser um instrumento importante para a superação do fracasso escolar. Discute aspectos da legislação brasileira sobre o tema $\mathrm{e}$ as possibilidades decorrentes do crescimento do conservadorismo político se opor a iniciativas a gestão democrática do ensino.

PALAVRAS-CHAVE: Gestão democrática. Gestão democrática do ensino. Legislação brasileira sobre educação. Fracasso escolar.

RESUMEN: El artículo discute la gestión de la enseñanza a partir del debate sobre la gestión democrática de instituciones sociales, en particular, la escuela. Refleja sobre los cambios ocurridos en la escuela en función de la presencia de nuevos alumnos, pertenecientes a las clases subalternas y la posibilidad de que la gestión democrática de la enseñanza sea un instrumento importante para la superación del fracaso escolar. Discute aspectos de la legislación brasileña sobre el tema y las posibilidades derivadas del crecimiento del conservadurismo político oponerse a iniciativas de la gestión democrática de la enseñanza.

PALABRAS CLAVE: Gestión democrática. Gestión democrática de la enseñanza. Legislación brasileña de la enseñanza. Fracaso escolar.

ABSTRACT: The article discusses the management of education from the debate on the democratic management of social institutions, in particular, the school. It reflects on the changes that have occurred in the school due to the presence of new students belonging to the subaltern classes and the possibility of the democratic management of teaching being an important instrument for overcoming school failure. It discusses aspects of

${ }^{1}$ Universidade Federal do Rio de Janeiro (Ufrj), Rio de Janeiro- RJ - Brasil. Professor Associado da UFRJ. E-mail: maxmasson@uol.com.br.

${ }^{2}$ Universidade Paulista (Unip), São Paulo - SP - Brasil. Professora da UNIP. E-mail: mariatvanacker@gmail.com.

RPGE - Revista on line de Política e Gestão Educacional, Araraquara, v. 22, n. esp.1, p. 84-104, mar., 2018 
Brazilian legislation on the theme and the possibilities arising from the growth of political conservatism oppose initiatives to democratic management of education.

KEYWORDS: Democratic management. Democratic management of teaching. Brazilian legislation of education. School failure.

\section{Introdução}

Tendo, somente de modo aparente, o seu cotidiano afastado dos confrontos mais intensos da sociedade - excetuando-se as consequências imediatas e geograficamente pontuais dos conflitos das grandes metrópoles do país - as escolas brasileiras, quase sempre dissimuladamente, vivenciam em seu interior tensões - e violências, por vezes até físicas, mas predominantemente simbólicas - cujas origens últimas se encontram nas relações de dominação entre classes sociais que marcam a história do Brasil.

Entretanto, em momentos, como os que têm sido vividos nos últimos anos, emergem no cenário escolar brasileiro, com força inusitada, disputas políticas e enfrentamentos ideológicos, que, à vista de outros entendimentos, reafirmariam a condição de "aparelho ideológico de estado" apontada nos escritos althusserianos dos anos setenta, contrariando visões idealizadas sobre, por fim, ter sido estabelecido no país consenso mínimo com relação aos objetivos educacionais a alcançar, entre os quais a "gestão democrática do ensino público e da escola", estando agora, nós brasileiros unidos "todos pela educação", como afirma conhecido slogan midiático.

Portanto, frente às incertezas de conjunturas em que se agravam as lutas no campo político, o debate sobre a noção de gestão democrática ganha dimensão particular, visto que sua compreensão incide, mesmo que de maneira mediata nas relações de poder presentes no campo educacional e, por consequência, no cotidiano das escolas e dos que as integram.

Nesse sentido, é necessário de início procuramos contextualizar as noções de gestão democrática e de gestão democrática do ensino, a fim de refletirmos sobre as possibilidades de, com algum grau de justeza, as empregarmos como categoria de análise e propostas de políticas públicas em educação, particularmente quanto aos processos de ensino e aprendizagem.

\section{Gestão democrática das instituições e da escola: pequena contextualização}


Quando, a partir sobretudo de meados do século XIX, os sistemas estatais de ensino se afirmaram no ocidente, passando a integrar o aparato do Estado moderno, tornando, por decorrência, a educação mais um dos objetos das políticas sociais ${ }^{3}$, assegurar os conhecimentos que a escola poderia vir a transmitir, considerando que isto não poderia nem deveria ser um privilégio de classe, tornou-se preocupação e aspiração de todos aqueles educadores que podemos agrupar sob a denominação de democratas e/ou progressistas, independente das perspectivas teóricas em que se fundamentavam ou do ideário político que abraçavam ${ }^{4}$.

Essa aspiração ganhou dimensão particular quando a universalização do acesso à escola e a ampliação dos percursos escolares, independente das origens sociais dos estudantes, se efetivaram ${ }^{5}$, principalmente após o fim da segunda guerra mundial; primeiro nas sociedades capitalistas avançadas e posteriormente, já mais ao final do século, em sociedades com passado colonial e inserção no sistema capitalista internacional em condição dependente e associada, caso da brasileira.

Nas sociedades capitalistas avançadas, o processo de universalização do acesso à escola e aumento dos períodos de permanência na mesma, ocorreu em meio a reformas dos sistemas de ensino, geralmente sob inspiração de teor socialdemocrata, mesmo quando empreendidas por partidos políticos de outros matizes ideológicos. Nas diferentes modalidades nacionais de welfare state desenvolvidas no hemisfério norte durante os chamados "trinta anos gloriosos (1946-1973)" do capitalismo6 , a educação

3 Se Durkheim, em sua clássica apresentação das relações entre sociedade e educação (DURKHEIM, 1985), sublinhava que em todas as sociedades onde alguma forma de estado veio a se constituir, de pronto se estabeleciam relações entre este e a educação, Offe (1984) apontou a estreita relação entre as políticas sociais, em sua condição de políticas de estado nas sociedades capitalistas e a produção do assalariamento da força de trabalho.

${ }^{4}$ Com a constituição dos sistemas estatais de ensino e a efetiva ampliação de sua abrangência, as iniciativas particulares de escolarização que tinham como pressuposto a não submissão à regulação do estado, como os empreendimentos realizados por organizações e educadores anarquistas, foram progressivamente desaparecendo, não raro por força de repressão direta. O Estado moderno tornava-se um educador, ainda que suas ações educativas objetivassem, em princípio, a manutenção do status quo e o conformismo político como apontava a irada crítica de Marx em sua Crítica ao Programa de Gotha (MARX, 1981).

${ }^{5}$ Nas sociedades em que foram desencadeados processos políticos objetivando a construção de uma ordem social socialista, mesmo que posteriormente interrompidos, vieram a ser objetivos praticamente imediatos dos novos governos a universalização do acesso à escola e o combate ao analfabetismo.

${ }^{6}$ Ainda que não se possa de modo mais preciso classificar propriamente as políticas sociais realizadas em tal período nos EUA de políticas típicas do welfare state, a progressiva ruptura, ao menos em termos jurídicos formais, do apartheid oficial então existente, bem como ações objetivando o que nos governos Johnson se propagandeou como Great Society, podem ser consideradas como também possuindo em algum grau inspiração socialdemocrata.

RPGE - Revista on line de Política e Gestão Educacional, Araraquara, v. 22, n. esp.1, p. 84-104, mar., 2018 
escolar foi considerada além de instrumento de impulsão do crescimento econômico ${ }^{7}$, importante meio proporcionador de mobilidade social, em especial para segmentos sociais com percursos escolares tradicionalmente de menor duração e com destinos mais limitados, afora aqueles segmentos, cujas novas gerações passavam a ter, na prática, suas primeiras inserções no universo escolar como camponeses ou trabalhadores urbanos sem qualificação profissional, contribuindo, mesmo indiretamente, para maior conformação dos socialmente subalternos aos princípios normativos da ordem democrática liberal.

No entanto, a igualdade formal dos sistemas de ensino e seus discursos acerca do esforço e das qualidades cognitivas individuais foram, desde a década de 1970, objeto de críticas diversas nascidas nos universos acadêmicos anglo-saxão e francês.

Analistas como Michael Young, Basil Berstein, Samuel Bowles, Herbert Gintis, Michael Apple e Pierre Bourdieu, demonstravam o quanto havia de dominação de classe nas estruturas dos sistemas de ensino do capitalismo avançado, o qual terminava por legitimar tal dominação em nome da incapacidade intelectual e/ou cultural dos socialmente subalternos. Mesmo com a reformulação dos currículos e modernização das normas escolares, persistiam práticas discriminatórias, que negavam no cotidiano escolar as esperanças de superação de preconceitos de classe, gênero e etnia manifestos nos discursos das agências governamentais ${ }^{8}$. Nas sociedades latino-americanas nomes como Ivan Ilitch e Paulo Freire emergiam como proponentes de novas práticas educacionais, criticando duramente a continuidade, mesmo quando disfarçada, do tradicionalismo pedagógico e de seus efeitos na reprodução das desigualdades sociais ${ }^{9}$.

Leituras de inspiração frankfurtiana, gramsciana, etnometodológica, afora os trabalhos de Michel Foucault, intercruzavam hegemonia política e dominação ideológica, disciplinas e instituições, burocracias e conformismos. Questionava-se o poder das tecnocracias públicas e privadas e seu modo de administrar calcado em

\footnotetext{
${ }^{7}$ É no curso dos anos cinquenta que a teoria do capital humano se estabelece como elemento legitimador dos crescentes investimentos na educação pública, visto que apontava elos entre aumento da escolarização e elevação da produtividade da força de trabalho.

${ }^{8}$ Vinte e dois anos após a publicação de "A Reprodução" e depois de todas as mudanças que mudaram o cenário mundial, Bourdieu (2015) reafirmava a presença de uma "nobreza de Estado", que com base em seus "títulos de nobreza escolar" se autoconsiderava uma elite da "inteligência", crente em sua legitimidade para, com a arrogância de sua ignorância, intervir no campo intelectual e manter-se dominante no campo político.

${ }^{9}$ A crítica ao tradicionalismo pedagógico tem longa trajetória, na qual se destacam as proposições da Escola Nova, em particular as de John Dewey, embora perspectivas relativamente distintas, que enfatizaram a importância de práticas democráticas no cotidiano escolar, também devam ser enfatizadas como as de Homer Lane, Alexander Neil, Célestin Freinet, entre outros.
} 
princípios de inspiração taylorista e/ou fordista. Às verdades da "administração científica" se contrapunham movimentos, nascidos ou não no universo sindical, pautados pela defesa do autogoverno da "coletividade" ${ }^{10}$, proponentes de uma gestão democrática, aberta a interesses que estariam costumeiramente silenciados pelos aparatos burocráticos, conforme apontado por Sander (2011).

No espaço particular da educação escolar, como assinala Camini (2013), progressivamente a expressão gestão educacional vem a substituir a de administração escolar, em meio a proposições acerca novas formas de organização política e pedagógica das instituições que deveriam ter como fundamento a gestão democrática.

\section{Gestão democrática do ensino no Brasil}

Com o advento de um regime democrático liberal no Brasil ${ }^{11}$, após vinte e um anos de ditadura militar, tanto a Constituição Federal de $1988^{12}$ como a Lei de Diretrizes e Bases da Educação Nacional ${ }^{13}$, consagrariam, no ordenamento jurídico do Estado brasileiro, a gestão democrática do ensino público como princípio.

À primeira vista, se estabeleciam parâmetros para a resolução de duas problemáticas sempre presentes na história da educação brasileira. A primeira, a prática tradicional de considerar as políticas públicas, entre as quais, as educacionais, como políticas "de governo" e não "de estado". Ao se ter estabelecido nos dois principais instrumentos legais do país que regem a educação a gestão democrática do ensino (público) como um fundamento ordenador da ação de todos os entes federados (união, estados e municípios), se esperava que vicissitudes conjunturais não mais poderiam impedir a intervenção da sociedade na definição das ações educacionais, em especial,

10 Ainda que proposições favoráveis à presença ativa - a participação - de todos os agentes sociais diretamente abrangidos em algum grau pelas ações de uma instituição nas formas da mesma ser governada, seja, de modo geral, percebida como possuindo uma conotação "coletivista", devemos nos recordas das considerações de Bobbio (1985) sobre as relações entre a democracia moderna e concepções individualistas da sociedade, dado que a primeira vem a ser base para a garantia política dos interesses do indivíduo.

11 Não empregamos a expressão "redemocratização", visto que ao longo de quase toda república, não tivemos efetivamente um regime democrático liberal, seja pela exclusão oficial da participação política de elevada parcela da população que, por força do analfabetismo, era excluída de toda participação política oficializada (não podia participar dos processos eleitorais bem como estava impedida de se organizar em partidos políticos), seja também por não haver livre organização partidária no país. Por quase toda sua história, o Partido Comunista do Brasil e outras organizações de matiz ideológico similar eram consideradas ilegais.

${ }^{12}$ Conforme disposto em seu artigo 206, a gestão democrática, na forma da lei, se constitui em princípio do ensino público.

${ }^{13}$ Conforme disposto nos artigos 3, 14 e 56 da Lei Federal 9394, de 20 de dezembro de 1996. 
aquelas empreendias no âmbito das instituições diretamente responsáveis pela oferta do ensino, ou seja, as escolas e as instituições de educação superior.

A segunda problemática, a reprodução no universo das instituições de ensino de práticas autoritárias, em particular por parte de gestores locais, as quais eram alimentadas tanto pelas tradições mandonistas e clientelísticas, heranças, em última instância, de um passado escravista, que marcam a esfera pública brasileira, como pela adoção, sobretudo durante o período ditatorial militar ${ }^{14}$, de noções taylor-fordistas de organização dos processos de trabalho e administração empresarial. Essas noções legitimavam, mediante sua pretensa cientificidade, a habitual concentração do poder de tomada de decisão nas mãos de dirigentes e de seu staff próximo, desqualificando, por presumida incompetência ou ignorância, quaisquer intervenções advindas daqueles que se encontravam em posição hierarquicamente inferior no interior da instituição. No caso da escola, esses últimos seriam os estudantes e seus familiares, os funcionários não docentes, os professores e a circunvizinhança da escola.

Ao se adotar o princípio da gestão democrática, afirmou-se também a obrigatoriedade da participação do conjunto dos profissionais da educação no projeto pedagógico da escola bem como das "comunidades escolar e local em conselhos escolares ou equivalentes" $"$. Formalmente, em termos legais, estaria superada a possibilidade de perpetuação de práticas autoritárias na gestão das instituições de ensino.

Entretanto, a legislação brasileira referente à educação ou mesmo à gestão do aparelho burocrático-administrativo não apresenta definição ou elementos balizadores de maior precisão sobre o que pode ser considerado como "gestão democrática do ensino". De maneira geral, é afirmada a necessidade da participação, de modo especial, como acima referido, na elaboração do projeto pedagógico da instituição (publica) e na constituição de conselhos escolares (também em instituições públicas), nos quais deverão se fazer presentes representações das comunidades escolar e local ${ }^{16}$.

14 A difusão de práticas de gestão dos estabelecimentos de ensino fundamentadas nos princípios da "administração científica" aplicada a escolas antecede ao golpe de $1^{\circ}$ de abril de 1964, como exemplifica parte da produção acadêmica presente no pioneiro periódico "Revista de Pedagogia", publicado pela Universidade de São Paulo, sobre educação escolar e políticas a esta pertinentes.

15 Conforme o artigo 14 da Lei Federal 9493, de dezembro de 1996, e que não sofreu alterações posteriores, nem mesmo aquelas decorrentes do golpe de estado de 2016.

${ }^{16}$ Nem mesmo documentos oficiais destinados à concretização da gestão democrática ultrapassam o teor de elevada generalidade presente em diversos trabalhos do campo educacional sobre a temática. Podemos mesmo dizer que ainda hoje não encontramos maiores alterações do que o formulado há já alguns anos sobre a questão, o que pode ser exemplificado, seja em documentos oficiais (BRASIL, 2004), seja em trabalhos acadêmicos do campo educacional (CURY, 2007). 
O elevado grau de generalidade da noção de gestão democrática, talvez impossível de ser efetivamente ultrapassado em termos de ato legal, nos permite formular duas questões relacionadas à educação escolar brasileira.

A primeira, por que a gestão dos sistemas de ensino (e consequentemente dos estabelecimentos que os integram) deve ter a obrigatoriedade de ser democrática exclusivamente para os sistemas públicos?

Embora "livre à iniciativa privada", conforme disposto na Constituição Federal ${ }^{17}$, as instituições de ensino privadas se encontram sob a regulação do Estado, visto que devem "o cumprimento das normas gerais da educação nacional"18. Não devendo estar obrigadas a ter a gestão segundo os procedimentos próprios da "gestão democrática do ensino", pode-se depreender que esta não se constitui em norma geral da educação nacional. Se nos momentos em que da elaboração tanto da Constituição de 1988 como da Lei de Diretrizes e Bases de 1996, principalmente no tocante à primeira, representações das escolas privadas conseguiram reagir ao que classificavam como ingerências indevidas na administração de estabelecimentos de suas propriedades, conforme salienta Camini (2013), em conjunturas em que cresce o conservadorismo político a própria formulação legal, ainda que bastante genérica, sobre a obrigatoriedade da gestão do ensino público ser "democrática" pode se tornar objeto de críticas reacionárias e até mesmo de propostas de revogação.

Considerando que para o senso comum a escola privada é qualitativamente superior à escola pública e que a primeira não está sob a exigência da gestão democrática, em nome da qualidade, pode-se eliminar esta obrigatoriedade nos sistemas públicos de ensino, substituindo-a por formas mais próprias aos princípios da gerência empresarial, desconsiderando as diferenças de propósito entre a instituição de ensino e a empresa capitalista ${ }^{19}$. Contribui para a concretização de tal possibilidade a progressiva mudança no enfoque dado à análise das instituições de ensino. Se anteriormente centrava-se na adequação do cotidiano institucional a normatizações padronizadas estabelecidas pelo poder público, nas últimas décadas, ganhou maior significado os resultados obtidos pelas instituições, secundarizando a importância da obediência a

${ }^{17}$ Veja-se o artigo 209 da Constituição Federal (BRASIL, 1988).

${ }^{18}$ Veja-se o inciso II do artigo 209 da Constituição Federal (BRASIL, 1988).

${ }^{19}$ Não se trata de fazermos uma crítica ingênua aos procedimentos administrativos empresariais, nem por sua vez, desconsiderarmos os inúmeros problemas dos sistemas públicos de ensino, sobretudo os decorrentes de imposições tomadas em nome do equilíbrio fiscal, mas sim de apontarmos como a gestão democrática do ensino pode se constituir em importante instrumento para a elevação da qualidade do ensino nacional.

RPGE - Revista on line de Política e Gestão Educacional, Araraquara, v. 22, n. esp.1, p. 84-104, mar., 2018. 
procedimentos padronizados. Ao se assim proceder, legitima-se o emprego de avaliações externas como instrumento principal de análise da qualidade das políticas educacionais e dos agentes institucionais que as executariam, no caso da escola, seus gestores e professores.

Nessa perspectiva, o debate sobre a gestão democrática do ensino, diretamente relacionado à democratização da educação escolar e suas instituições, implica em discutir os objetivos que se pretende com as atividades de ensino, os interesses a estas relacionados e, segunda questão: por quais motivos alguns desses interesses seriam mais propensos a se concretizar com a "gestão democrática do ensino"?

Ainda que implicitamente haja uma ampla discussão sobre a afirmação que se segue, só há efetivo sentido na proposição da gestão democrática do ensino, independente se em instituições escolares públicas ou privadas, se essa forma de gerir os processos de ensino possibilitar aprendizados qualitativamente mais significativos, em que os que se destinam a aprender o façam como maior eficácia, com maior capacidade de compreensão das inúmeras facetas da realidade, que compõem, ainda que não exclusivamente, o conjunto das disciplinas escolares integrantes dos currículos escolares. Desse modo, pensar em gestão democrática do ensino necessariamente implica em discutir os objetivos do ensino escolar e os procedimentos a ele inerentes, em especial quando próprios ao espaço da escola.

\section{Gestão do ensino e democratização da educação escolar}

Nas sociedades contemporâneas a oportunidade para todos de acesso e da compreensão dos conhecimentos socialmente produzidos e de sua compreensão se constitui em objetivo político de caráter democrático essencial, em particular para os agentes sociais que integram as classes posicionadas no polo inferior do campo social.

Isto implica necessariamente na luta pela democratização da escola (e igualmente da gestão do ensino que esta oferece); no enfrentamento do fracasso escolar mediante o trabalho pedagógico e a transformação da cultura escolar, não se admitindo como naturais nem a constituição de hierarquias de excelência institucional (em nosso caso, escolar) nem uma "distribuição de talentos" na hierarquia social por efeito de pretensos dons individuais (BOURDIEU, 1996b). É preciso romper com a ideologia do dom (e da vocação natural das instituições de ensino) que transforma as desigualdades 
dos agentes sociais frente às formas de capital cultural consideradas socialmente legítimas em desigualdades de aprendizagem ${ }^{20}$.

Os estudos da sociologia da educação mostram que uma escola pode ser eficaz tanto por produzir maior igualdade social, quanto por enfatizar a reprodução das desigualdades. Em geral, o discurso político de legisladores e educadores - na escola e nas universidades - explicitam a expectativa de que a política educativa (no plano governamental) ou os projetos e práticas pedagógicas (no plano institucional) possam produzir efeitos diferenciadores em relação às desigualdades sociais. Ainda que não tenhamos a ilusão de que a instituição escolar possa se sobrepor aos determinantes estruturais das sociedades capitalistas, há estudos que mostram sua importância na superação de dificuldades individuais produzidas, sobretudo ainda que não somente, pelas relações entre as classes sociais $^{21}$. Porém, para isso não basta o acesso à escolarização. Verifica-se, tanto no Brasil, quanto em outras regiões do mundo, que a expansão do acesso à escola veio acompanhada da crise de eficácia da ação socializadora da instituição escolar, expresso pelo senso comum em falas como: "a escola não é como antigamente", com sentido negativo, significando, frequentemente que a escola não ensina como o fazia e que não tem mais o papel positivo que tinha, em virtude principalmente da mudança de clientela e das formas como se processam diferenciadamente os percursos escolares.

Essa visão redutora e simplificadora idealiza o sucesso da escola de "antigamente", esquecendo-se do quanto restritiva era a escola, tanto em termos diretamente de classe, como também no tocante a sexo e etnia e desconsidera a complexidade das questões envolvidas no ensino e na aprendizagem. Entretanto, escola pode ter um papel positivo na superação dessas dificuldades ao considerar a condição de aluno como um processo de transformação: "não se nasce aluno, torna-se aluno" (Agnes Van Zanten e Duru Bellat, 1992 apud SPÓSITO, 2013)

Considerar a condição de aluno para esses dois autores (Van Zanten e Bellat) implica em três pressupostos.

O primeiro resulta da compreensão do que denominamos trabalho escolar. Este está relacionado a expectativas implícitas de professores e da instituição escolar, mas

20 Perrenoud (2000) emprega a expressão “diferenciação selvagem” para caracterizar a diferenciação involuntária, não objetivamente construída, dos percursos escolares dos alunos das escolas de educação básica, que para a grande maioria dos socialmente subalternos tende a se constituir em experiências diferenciadas de fracasso escolar.

${ }^{21}$ Nesse sentido, veja-se o clássico trabalho de Lahire sobre trajetórias escolares bem sucedidas de crianças e jovens das classes populares em princípio fadados ao insucesso na escola.

RPGE - Revista on line de Política e Gestão Educacional, Araraquara, v. 22, n. esp.1, p. 84-104, mar., 2018 
também - e sobretudo - aos modos como os alunos compreendem as atividades que constituem o trabalho escolar. Por consequência, a aprendizagem deve ser compreendida de forma mais complexa. Ela não é uma decorrência imediata e linear do ensino. A ação dos alunos não se restringe a responder a exigências explicitadas por programas e regulamentos oficiais.

A partir deste primeiro pressuposto, decorre o segundo.

Em suas ações cotidianas na escola, o aluno incorpora o conjunto de percepções que elabora em sua socialização extraescolar, ou seja, em outros espaços de interação social como, por exemplo, a família. Implícitas a essas percepções encontramos orientações para a ação ou, empregando formulação de Pierre Bourdieu, dispositivos constituintes do habitus de classe do aluno, provenientes de sua posição no campo social em termos de classe, etnia e gênero. Dispositivos que quase sempre são incorporados de forma inconsciente ${ }^{22}$, mas cuja presença orienta suas ações no âmbito da escola, explicitando suas percepções tanto sobre a escola como de sua relação particular (individual) com a escola.

O terceiro pressuposto diz respeito a formas particulares de inserção do aluno no ciclo de vida - infância ou juventude - que se configuram como categorias específicas e com relativa autonomia na sociedade.

A partir desses pressupostos consideramos que as pesquisas sobre os processos que envolvem as ações dos alunos e suas relações com a gestão do ensino passam a ser cada vez mais importantes e estratégicas se se quer compreender porque a democratização do acesso à escola se faz acompanhada da produção da exclusão da apropriação do capital cultural legítimo sob forma escolar, notadamente dos socialmente dominados. Ainda que jovens estudantes desses segmentos sociais permaneçam por mais tempo no interior da escola, percepção da "exclusão no interior" da instituição provoca a emergência de sentimentos contraditórios em relação ao sentido da obrigatoriedade escolar. Se acreditamos na possibilidade de construir estratégias de gestão democrática tendo em vista enfrentar o desafio de proporcionar aos estudantes das classes populares a apropriação dos conhecimentos provenientes das disciplinas escolares, como é definido em diretrizes do Plano Nacional de Educação (2014-2024), ${ }^{23}$ aprovado pela lei 13005 de 25/06/2014: a promoção do princípio da gestão democrática

${ }^{22}$ De modo geral, quanto mais novos são os alunos menor é a possibilidade de autorreflexão acerca do seu agir, tornando possível ocorrer uma percepção naturalizada dos procedimentos realizados no espaço social, nas interações com outros agentes sociais.

${ }^{23}$ Veja-se Brasil (2014). 
na educação pública (item VI) e a melhoria da qualidade da educação. (item IV). Então as ações no âmbito da gestão do ensino, considerando as ações dos alunos, da escola e suas relações com o conhecimento escolar, tendo em vista a distribuição e produção de capital cultural, são fundamentais e necessárias.

O processo de exclusão do interior da escola (a progressiva construção do fracasso escolar) se faz acompanhado da desvalorização (e estigmatização) de determinadas unidades escolares, frequentemente, aquelas nas quais se concentram os alunos mais pobres e, em geral, também residentes em espaços geograficamente segregados $^{24}$. Este fenômeno passou a existir na medida em que a ampliação do acesso à escola atingiu um maior número de indivíduos oriundos de famílias cujas relações com as escolas são marcadas pelo distanciamento ou inacessibilidade.

Esses alunos são, muitas vezes, portadores de um capital cultural que se distingue ou mesmo secundariza os valores da cultura escolar ou, principalmente, que é negado pela da tradição escolar e seus valores de preponderância pequeno-burguesa ${ }^{25}$ Os integrantes das classes subalternas que ficavam ou fora da escola ou realizavam apenas percursos de pouca duração, agora não só passam a frequentá-la, como tendem a estender por maior tempo sua presença no interior da escola. No entanto, isto não lhes garante equiparação de condição social, ao contrário, ampliam-se essas diferenças e a escolarização continua sendo um instrumento de reprodução das distinções sociais, mediante a reconversão dos diplomas, como também assinalou Bourdieu (2010), fazendo com que os certificados, antes valorizados, após sua apropriação pelos socialmente subalternos passem a apresentar menor valor simbólico.

A expansão do tempo de escolaridade e as mudanças na organização dos processos de trabalho podem postergar o ingresso dos jovens no mercado trabalho, em especial no formal, ainda que não necessariamente no informal, ampliando a presença de jovens na escola por mais tempo, em função de estratégias familiares que somente

${ }^{24}$ Para uma análise aprofundada deste processo em sociedades capitalistas avançadas, veja-se o hoje clássico trabalho de Bourdieu e colaboradores (BOURDIEU, 1997).

${ }^{25}$ Embora a escola moderna tenha se constituído em meio aos processos de ascensão da burguesia à condição de classe dominante nas sociedades ocidentais, a instituição dos sistemas estatais de ensino que incorporou às diferentes camadas da pequena burguesia, produziu, por efeito de inversão, a dominância no espaço escolar de valores mais pertinentes a essas camadas do que propriamente às frações superiores da burguesia, conforme sublinhou Bourdieu, os procedimentos "escolares" não possuem grande reconhecimento no campo intelectual e em especial, no campo artístico, espaços em que predominam valores mais pertinentes a visões de mundo burguesas. Nesse sentido, veja-se: Bourdieu (1996; 2007; 2011).

RPGE - Revista on line de Política e Gestão Educacional, Araraquara, v. 22, n. esp.1, p. 84-104, mar., 2018 
vêm a ser efetivamente quando há maiores possibilidades de emprego e elevação do valor real dos salários, mesmo que de maneira minimizada ${ }^{26}$.

Hoje, a presença de jovens na escola de massa significa o desafio de conviver no seu interior com um público que traz para a instituição um modo distinto das diferentes formas anteriores de interação.

Conforme assinalam Barrère e Martucelli, citados por Sposito (2013, p. 441), afora a questão do acesso das classes subalternas à escola, há também a presença de uma subcultura adolescente que engendra reticências ou oposição à ação do universo normativo escolar. Essa tensão entre duas sub culturas - a dos adultos, representantes da instituição, e a da juventude - provoca transformações na modelação da escola.

Boa parte dos jovens estudantes não encontram grandes referências na cultura escolar, seja por força do pertencimento de classe, seja por mudanças no comportamento das classes frente à escola.

Os critérios da sociabilidade adulta passam a ser confrontados pela cultura juvenil, particularmente quando se sucedem anos de instabilidade econômica e de flexibilização das relações de trabalho, produzindo sensações de incerteza quanto às perspectivas de futuro e relativização da importância da educação formal para o sucesso em suas vidas. Sensações que são perceptíveis inclusive naqueles segmentos sociais que historicamente reproduzem sua condição de classe mediante a escolarização prolongada como as vem a ser típico das camadas da pequena burguesia.

É diante, portanto, desse contexto a instituição escolar deverá responder ao dilema de se afirmar como instituição a serviço do aprofundamento da exclusão social ou a serviço da democratização da sociedade, ampliando oportunidades efetivas de apropriação do conhecimento às classes dominadas.

Do ponto de vista do ensino, desde o início do século XX os métodos ativos em educação foram propostos no sentido de ampliarem as oportunidades das classes populares, afirmando o protagonismo dos alunos nos processos de aprendizagem. Entretanto, essas características da Escola Nova chegaram a ser consideradas, equivocadamente, impossíveis de atingir as massas e, nesse sentido, seriam intrinsecamente elitistas. Por sua vez, a perpetuação do tradicionalismo pedagógico sempre se constituiu em obstáculo à hegemonia das práticas propostas pela Escola Nova nas instituições de ensino. Apesar disso, ampliaram-se as experiências e os estudos

${ }^{26}$ Conforme assinala Pochmann (2012).

RPGE - Revista on line de Política e Gestão Educacional, Araraquara, v. 22, n. esp.1, p. 84-104, mar., 2018. 
sobre a importância das vivências sociais na aprendizagem - tanto no âmbito da psicologia cognitiva, quanto no âmbito das práticas escolares - quanto no âmbito das teorias do currículo.

Paralelamente às experiências de inovação ou de renovação de métodos de ensino e de organização da escola assistimos, desde o final do século XX, à permanência de uma concepção autoritária de ensino que ainda podemos encontrar no interior das instituições de ensino, e no discurso sobre a escola, especialmente presentes da defesa de programações rígidas (definidas sem levar em consideração as vivências dos alunos) de avaliações que negam processos individuais de aprendizagem, de propostas didáticas que enfatizam o esforço e desconsideram o interesse dos alunos, bem como suas experiências de aprendizagem nas várias situações da vida. Tais propostas de cunho autoritário, buscam controlar resultados do ensino, por meio de avaliações e definições de programas e, desse modo, promover uma gestão empresarial do ensino. Nesse contexto, surgem no Brasil, como em outros países, os índices de desempenho educacional que bonificam o trabalho dos professores, na rede pública ou o ranqueamento de escolas (particulares e públicas) a partir da divulgação dos resultados dos participantes no Exame Nacional do Ensino Médio, utilizado como instrumento seletivo para o ingresso em instituições de ensino superior. Todas essas práticas podem ser identificadas como mecanismos de distinção das escolas, de produção de desigualdades, contribuindo para a produção e reprodução da "exclusão no interior" da escola.

Neste sentido, propostas educacionais em qualquer esfera - nacional ou local visando objetivos democráticos pautados em interesses das classes sociais subalternas precisam ter em conta a categoria de igualdade. Marcio Pochmann e Eliza Bartolozzi Ferreira (POCHMANN; FERREIRA, 2016), discutem a relação entre esta categoria e as práticas educativas, em especial, as práticas e estratégias de ensino, as quais devem atentar para as experiências sociais dos alunos.

Na educação, a igualdade não é concebida como um princípio abstrato, mas como uma crítica às desigualdades. Pensar uma educação igual não é desejar uma igualdade perfeita, que é utópica; mas é querer reduzir uma parte das desigualdades em face à instrução, que podem ser ligadas ao território onde se vive, à origem social, ao sexo, à religião etc. As diferenças de condições entre os indivíduos não devem ser definitivas. Somente a igualdade em direitos é definitiva e o objetivo de uma sociedade justa é dar a possibilidade, a cada um, de escolhas e de encontros com o novo. As diferenças sociais não devem ser ligadas nem à nascença, nem à

RPGE - Revista on line de Política e Gestão Educacional, Araraquara, v. 22, n. esp.1, p. 84-104, mar., 2018. 
fortuna dos pais, nem aos hábitos culturais, nem à religião, nem ao sexo, nem à cor da pele etc. Todas as discriminações devem ser combatidas. A igualdade de direitos deve garantir o poder da escolha para cada cidadão. (POCHMANN; FERREIRA, 2016, p. 1241)

Tais considerações sobre a igualdade devem ser compreendidas no contexto da história da educação brasileira. Apenas com a Constituição de 1988 (ainda que outras conquistas anteriores houveram) a educação passou a ser considerada direito social inalienável, tendo por base a concepção de educação como processo de formação humana. A mesma Constituição define responsabilidades dos entes da federação em prover condições de ensino, bem como estabelece vinculação de recursos financeiros para a educação.

No entanto, a despeito do grande número de programas e políticas educacionais e dos investimentos realizados, ainda assim a igualdade no direito à educação não corresponde à igualdade de chances revelada pela não permanência na escola e pela diferenciação dada os diplomas ou as instituições de ensino - fortes ou fracas. Nesse sentido, as políticas compensatórias, bem como tratamento diferenciado nas várias escolas, cumpririam um papel importante para conseguirmos maior equidade social.

Equidade não significa o mesmo que distribuição em partes iguais para todos. Para Pochmann e Ferreira, a equidade do sistema educativo não deve ser avaliada apenas a partir de critérios internos (número de aulas, número de vagas, etc), mas devese levar em consideração seus efeitos sociais e os meios de se atingir os mesmos benefícios para todos, pois para esses autores justiça com equidade significa favorecer aqueles que integram as classes subalternas, constrangidos historicamente à condição de dominados.

A partir do contexto da escola de massa e do aprofundamento de mecanismos de desigualdades que produzem o que chamamos de exclusão do interior, como poderiam as ações educativas, no âmbito das unidades escolares, contribuir para minimizar efeitos da desigualdade social, objetivando possível superação futura?

Em que medida a gestão democrática do ensino público, tal como é tratada pela LDB, oferece brechas e instrumentos legais, por meio dos quais é possível traçar estratégias de práticas que permitam uma gestão do ensino na unidade escolar?

Os antes mencionados artigos 14 e 15 da Lei de Diretrizes e Bases da Educação (Lei $\mathrm{n}^{\circ} 9394$ de 20 de dezembro de 1996), apesar das recentes medidas de teor conservador e socialmente excludentes, ainda permanecem inalterados. O artigo 14 
regulamenta dois princípios norteadores das normas da gestão democrática na educação básica a serem definidas pelos sistemas de ensino. Um privilegia a participação dos profissionais da educação aos quais cabe papel ativo na elaboração do projeto pedagógico da escola; o outro reserva um papel também ativo à comunidade escolar e local em conselhos da escola.

Nos deteremos aqui na importância das considerações do artigo 15 sobre a autonomia pedagógica, ainda que relativa, das unidades escolares públicas de educação básica para a efetividade da gestão democrática e o papel das questões de ensino nos projetos pedagógicos das escolas.

Cabe ressaltar que é no âmbito do projeto pedagógico da escola que se pode decidir sobre as atividades que serão executadas, no contexto disciplinar, para um determinado grupo de alunos, ou seja, as práticas e atividades de ensino, podem se configurar como um projeto pedagógico que individualiza e responde a desafios de uma dada unidade ensino. Este poderá ser apenas um instrumento de gestão realizado para cumprir determinações legais, ou poderá ser, efetivamente um instrumento de gestão da escola, do ponto de vista do ensino, considerando as possibilidades da ação docente e a perspectiva da aprendizagem dos alunos.

Gerir a escola do ponto de vista do ensino não significa afirmar a voz única dos professores sobre alunos considerados como tábula rasa. Significa, em oposição a essa ideia, agir estrategicamente a partir da compreensão da função do ensino na escola contemporânea, da sua relação com a cultura, da importância da seleção e ênfase de conteúdos significativos na sociedade complexa em que vivemos. Diante de tantas questões a enfrentar, parece-nos que o projeto político pedagógico, previsto e valorizado na perspectiva da gestão democrática da escola, pode ser instrumento facilitador da tomada de decisões, da integração entre as disciplinas e da construção de estratégias de ensino e de acompanhamento da aprendizagem dos alunos, considerando inclusive as mudanças nas relações entre jovens e a escola que acima mencionamos.

Cabe ressaltar que o ensino é uma atividade orientada para uma meta, cujo êxito pode estar muito além dos limites da própria atividade. Ou seja, o ensino é um fenômeno independente da aprendizagem, tem características próprias, não pode ser medido pela aprendizagem dos alunos e, no entanto, essa é sua intenção. O ensino se dá assim em condições particulares, em cada escola, com sua cultura própria, assim como a distribuição do espaço, e entre o que se quer ensinar e o que os alunos aprendem.

RPGE - Revista on line de Política e Gestão Educacional, Araraquara, v. 22, n. esp.1, p. 84-104, mar., 2018 
Considerar essa questão do ponto de vista de uma possibilidade de gestão democrática é refletir sobre uma tradição escolar na qual as considerações sobre a diversidade dos alunos e de seus modos de aprender estiveram ausentes do pensamento sobre a aprendizagem na escola pública marcada pela ideologia meritocrática, ou seja, o ensino era igual para todos e os bem-sucedidos o eram por mérito. Os testes mediam graus e parâmetros de normalidade. As desigualdades eram vistas como algo natural, e não como marcas da diferença social, de classe. Havia os que tinham aptidão e os que não a tinham. Tudo era uma questão de característica essencial e hereditária. Construíase com esse conceito uma ideologia justificadora da desigualdade social, não questionada, uma vez que, eventualmente, alguns indivíduos das camadas populares demonstravam tais aptidões e, até, se sobressaíam, fato que reforçava a definição do padrão de normalidade e reiterava a desigualdade social.

\section{Observações finais}

Um dos objetivos que legitimam a existência da escola moderna é possibilitar aos que nela se encontram desenvolver a faculdade de se defrontar com o inédito e buscar compreendê-lo por meio do emprego dos conhecimentos disponíveis para interpretar a realidade e mediante um distanciamento do senso comum. Portanto, desenvolver a capacidade de problematizar situações dadas da realidade e de produzir hipóteses que permitam vir a sua compreensão.

Isto não se consegue mediante exercício rotineiros reproduzidos eternamente, seguidamente, sem que os alunos possam vir a depreender os problemas com que se defrontam nas diferentes disciplinas escolares, percebendo ao final que os conhecimentos, sobretudo os menos imediatos, são respostas racionalmente produzidas, portanto construções humanas a questões que se apresentaram na história dos homens e não descobertas casuais de indivíduos de inteligências excepcionais.

Para tal, a escola deve como propósito fazer com que os alunos sejam capazes de reconhecer e empregar seus recursos cognitivos, desenvolvendo estratégias de aprendizagem, fundamentais não somente para aqueles que não herdaram o capital cultural considerado legítimo como também para alunos de classes posicionadas de modo superior no campo social. Ainda nos deparamos com a força do tradicionalismo pedagógico que secundariza a contextualização e problematização, priorizando o reconhecimento e a memorização de soluções (fórmulas) a partir de suas situações 
formalizadas, não problematizadas. Nesse sentido, ainda que oficialmente a escola trabalhe com conhecimentos oriundos das ciências, visões dogmáticas, pré-científicas podemos mesmo dizer, permanecem muito presentes no cotidiano escolar.

Uma proposta de democratização da gestão da escola e do ensino passa necessariamente pela produção de condições de superação dos princípios constituintes do senso comum - mediante as práticas de uma pedagogia radicalmente racional, segundo Pierre Bourdieu ${ }^{27}$ - não para excluí-lo da cena escolar, pois além de tal propósito ser em tudo utópico e inconsistente, como apontou Freire é necessário colocar ao

[...] professor ou mais amplamente à escola, o dever de não só respeitar os saberes com que os educandos, sobretudo os das classes populares, chegam a ela - saberes socialmente construídos na prática comunitária - mas também, como há mais de trinta anos venho sugerindo, discutir com os alunos a razão de ser de alguns desses saberes em relação9 com o ensino dos conteúdos (FREIRE, 1996, p. $30) .^{28}$

Proposições de gestão do ensino em tal sentido, exigem para que sua radicalidade democrática se efetive que haja uma gestão coletivo do ensino, portanto, projetos que não se fundem em ações individuais, por mais consistentes e comprometidas que possam ser, bem como tenham por intuito superar a fragmentação estanque dos saberes e disciplinares escolares, que a tradição escolar produziu e que se perpetua gerando ainda que nunca oficialmente afirmada uma hierarquização das disciplinas e competições dissimuladas no interior do corpo docente, apesar de todas as afirmações sobre a importância dos trabalhos interdisciplinares.

Por fim, salientamos que um dos tradicionais reclamos dos gestores das escolas das redes públicas é a pequena participação de pais ou responsáveis dos alunos no cotidiano das escolas, principalmente nos centros urbanos de maior dimensão, fato também registrado na literatura educacional nacional. Tradicionalmente essa ausência de participação ou alheamento do cotidiano das escolas de seus filhos é compreendida, pelo senso comum escolar como decorrente do menor capital cultural de pais e responsáveis dos alunos, os quais não se sentiriam em condições de intervir na gestão da

27 Elementos não plenamente sistematizados de uma proposição que se aproximaria de tal intento pedagógico podem ser apreendidos no que denominou de princípios para uma reflexão sobre os conteúdos do ensino (BOURDIEU, 2015, p. 241-250).

${ }^{28}$ Nos limites deste artigo não nos é possível analisar as possibilidades de emprego conjunto de dois autores, à primeira vista, não somente distintos como posicionados de forma quase antagônica em suas apreensões das práticas educacionais escolares, como Bourdieu e Freire. Trabalho, ainda que em nosso entendimento, não de todo suficiente, veio a ser o de Burawoy (2004).

RPGE - Revista on line de Política e Gestão Educacional, Araraquara, v. 22, n. esp.1, p. 84-104, mar., 2018 
escola e muito menos no tocante ao ensino, excetuando-se assuntos como inexistência de professores ou atitudes excessivamente ríspidas envolvendo alunos e professores. A participação dos pais tende a assumir a forma de "ajuda" em campanhas, festas e eventos similares. De maneira algo mais sofisticada, esse baixo interesse em participar mais amiúde dos processos de gestão pode ser atribuída a uma espécie de atrofia do político $^{29}$, uma apatia decorrente dos modos como as democracias representativas terminam por delimitar a ação política da grande maioria da população (BOBBIO, 1996), situação que, no caso brasileiro, seria agravada pela presença, simultânea, de práticas autoritárias e clientelísticas, as quais em nada propiciariam à participação na gestão das instituições, mesmo daquelas em que interesses mais diretos de próximos, como seus familiares, são afetados, como vem a ser o caso das escolas.

Entretanto, tema que apenas fazemos menção por força dos limites de espaço, emergem na sociedade brasileira manifestações de novo tipo, as quais tendem a interferir expressivamente no cotidiano das escolas, independente destas serem públicas ou privadas. Referimo-nos a crescente pressões e intervenções de ativismo político conservador, que tem por adeptos tanto aqueles que pertencem a camadas das classes médias como também integrantes das classes populares. Esse ativismo conservador tem se caracterizado pela posse de capital político próprio, propriedade bastante distinta dos membros da clientela escolar (pais ou mesmo alunos) que mais comumente participam de ações ou de órgãos vinculados à gestão da escola e do ensino que esta oferece.

Como tem sido noticiado pelas chamadas redes sociais ou órgãos da imprensa e denunciado por sindicatos de professores e organizações políticas situada à esquerda no campo político, muitas das ações deste novo ativismo político tem ocorrido de maneira extraescolar, na esfera do judiciário (geralmente sob a formas de denúncias ou ações contra membros do magistério) ou do legislativo (mediante proposições que restringem a liberdade de ensino e são geralmente associadas ao ultraconservador movimento denominado "escola sem partido", nascido ainda na primeira década do atual século, mas que ganhou dimensão maior no revigoramento da direita no Brasil.

Por sua vez, no âmbito mais interno das escolas, reiteremos independente destas serem públicas ou privadas, o ativismo político conservador, notadamente com feição

${ }^{29}$ A baixa participação da população, sobretudo das classes populares, na esfera pública, não impede a ocorrência de manifestações pontuais - e de expressões conjunturais significativas - como é exemplo recente no campo educacional brasileiro os movimentos estudantis de ocupação de escolas, os quais não raro têm se defrontado, inclusive nas próprias escolas, com reações que nos lembram das considerações de Gramsci sobre o conformismo de instituições que se assemelhariam a verdadeiras casamatas ideológicas. 
religiosa, tem realizado intervenções que afetariam mais diretamente a gestão do ensino, por incidirem sobre conteúdos curriculares. Afora manifestações de teor regressista e de caráter homofóbico, conteúdos programáticos de disciplinas escolares como, por exemplo, história, particularmente no referente a história dos povos africanos e de manifestações culturais brasileiras, têm sido alvo não apenas de questionamentos mas de atos que embora aparentem mesclar "somente" ignorância e intolerância, na verdade possuem forte conotação racista por parte de pais e também de estudantes, possibilitando que, progressivamente, se configure ambientes de tensão e medo nas escolas. Aos tradicionais obstáculos à conformação de processos de gestão democrática da escola e do ensino, a educação brasileira se defronta com elementos que provavelmente dificultarão ainda mais a superação de situações escolares que alimentam a reprodução das desigualdades sociais mediante a difusão de estereótipos e preconceitos que, em última instância, induzem a forte conformismo político as classes populares. Desse modo, os conflitos do campo político cuja ampliação da intensidade se encontra ainda indefinida instalam-se, sob forma específica, no campo educacional, podendo o domínio conservador, caso este se consolide, significar passos atrás na democratização da educação escolar brasileira.

\section{REFERÊNCIAS}

BOBBIO, N. O futuro da democracia: uma defesa das regras do jogo. Tradução de Marco Aurélio Nogueira. Rio de Janeiro: Paz e Terra, 1986.

BOURDIEU, P. As regras da arte: gênese e estrutura do campo literário. Tradução de Maria Lúcia Machado. São Paulo: Companhia das Letras, 1996.

BOURDIEU, P. Marginália: algumas notas adicionais sobre o dom. Tradução de Stela dos Santos Abreu. In: Mana: Estudos de Antropologia Social, v. 02, n. 02, out., 1996b, p.07-17.

BOURDIEU, P. Las estrategias de la reprodución social. Tradução de Alicia Beatriz Gutiérrez. Buenos Aires: Siglo Veintiuno, 2011.

BOURDIEU, P.; Wacquant, L. Una invitación a la sociología reflexiva. Tradução de Ariel Dilon. Buenos Aires: Siglo Veintiuno Editores, 2012.

BOURDIEU, P. Intervenciones políticas: um sociólogo em la barricada. Tradução de Alicia Beatriz Guitérrez. Buenos Aires: Siglo Veintiuno Editores, 2015. 
BOURDIEU, P.; BOLTANSKI, L. O diploma e o cargo: relações entre o sistema de produção e o sistema de reprodução. Tradução de Magali de Castro. In: Escritos de educação. Organização de Maria Alice Nogueira e Afrânio Catani. Petrópolis-RJ: Vozes, 2010, $11^{a}$ edição.

BOURDIEU, P. et al. A miséria do mundo. Tradução de Mateus S. S. Azevedo, Jaime A. Clasen, Sérgio H. de F. Guimarães, Marcus A. Penchel, Guilherme J. de F. Teixeira e Jairo V. Vargas. Petrópolis-RJ: Vozes, 2003, 8 edição.

BRASIL. Constituição (1988). Constituição da República Federativa do Brasil. Brasília, DF: Senado Federal, 1988.

BRASIL. Lei $\mathbf{n}^{\mathbf{0}}$ 13.005, de 25 de junho de 2014. Aprova o Plano Nacional de Educação - PNE e dá outras providências. Brasília: Senado Federal, 2014. Disponível em: <http://www.planalto.gov.br/ccivil_03/_ato2011-2014/2014/lei/113005.htm>. Acesso em: 10 set. 2017.

BRASIL. Ministério da Educação. Secretaria de Educação Básica. Programa Nacional de Fortalecimento dos Conselhos Escolares. Gestão da educação escolar. Brasília: UnB, CEAD, 2004, volume 5. p. 25).

BURAWOY, M. Pedagogy of the oppressed: Freire Meets Bourdieu. Berkeley, 2004. Disponível em: <http://burawoy.berkeley.edu/Bourdieu/6.Freire.pdf >. Acesso em: 10 ago. 2017.

CAMINI, L. Política e Gestão Educacional Brasileira: uma análise do Plano Nacional de Desenvolvimento da Educação/Plano de Metas Compromisso Todos pela Educação (2007/2009). São Paulo: Outras Palavras, 2013.

CURY, C. R. J. A gestão democrática na escola e o direito à educação. Revista Brasileira de Política e Administração da Escola, v. 23, n. 3, p. 483-495, set./dez., 2007.

DURKHEIM, E. Sociologia, educação e moral. Tradução de Evaristo Santos. Porto: Rés Editora, 1984.

FREIRE, P. Pedagogia da autonomia. Saberes necessários à prática educativa. São Paulo: Paz e Terra, 1996.

LAHIRE, B. Sucesso escolar nos meios populares: as razões do improvável. Tradução de Ramon Américo Vasques e Sonia Goldfeder. São Paulo: Ática, 1997.

MARX, K. Crítica ao Programa de Gotha. In: Marx y Engels, Obras Escogidas, Tomo III. Tradução espanhola. Moscou: Editorial Progreso, 1981.

OFFE, C. Problemas estruturais do estado capitalista. Tradução de Bárbara Freitag. Rio de Janeiro: Tempo Brasileiro, 1984.

PERRENOUD, P. Pedagogia diferenciada: das intenções à ação. Tradução de Patrícia Chittoni Ramos. Porto Alegre: Artes Médicas Sul, 2000. 
POCHMANN, M. Nova classe média? O trabalho na base da pirâmide social brasileira. São Paulo: Boitempo Editorial, 2012.

SANDER, B. Estado do conhecimento em perspectiva. In: MARTINS, A. M. (Org.). Estado da Arte: gestão, autonomia escolar e órgãos colegiados (2000-2008). Brasília: Liber Livros/ANPAE, 2011.

SPÓSITO, M. P. Interfaces entre a sociologia da educação e os estudos sobre a juventude no Brasil. In: APPLE, M.; BALL, S.; GANDIN, L. A sociologia da educação: análise internacional. Porto Alegre: Penso, 2013.

\section{Como referenciar este artigo}

MASSON, Máximo Augusto Campos; VAN ACKER, Maria Teresa Vianna. Educação escolar e gestão democrática do ensino: perospectivas. Revista on line de Política e Gestão Educacional, Araraquara, v. 22, n. esp.1, p. 84-104, mar., 2018. E-ISSN:15199029.

Submetido em: 04/10/217

Aprovado em: 14/12/2017 